\section{Low-dose halothane produces airway dilatation but does not alter parenchymal mechanics in the normal canine lung}

H. Uchida $M D$, T. Mizuguchi MD
The purpose of this study was to examine whether halothane reduces the contractile tone of the normal lung and to distinguish the effects of halothane on airways from those on lung tissue. We also tested whether a mathematical model was capable of quantitatively describing the mechanical changes in the lung produced by halothane. We measured lung impedence ( $Z L(\omega)$ a complex function of real (hung resistance) and imaginary (reactance) parts) at low frequencies in dogs using a forced volume oscillation technique before and during I MAC halothane anaesthesia. Halothane produced small changes in $Z L(\omega)$. The lung resistance tended to decrease during halothane anaesthesia whereas the lung reactance did not show change. Using an alveolar capsule technique to separate the airways from the lung tissue components, these lung mechanical changes were induced mainly by alterations in lung tissue and not in the airways. Our mathematical model featured a single airway leading to an alveolar region surrounded by a viscoelastic lung tissue. In the model analysis, estimates of airway resistance and inertance decreased by the administration of halothane. In contrast, estimates of lung tissue elastance and resistance did not change during halothane anaesthesia. These modeling results were consistent with those obtained by direct alveolar pressure measurements. Our results suggest that a low concentration of halothane dilates the airways but does not alter the parenchymal mechanics in the normal lung, and that the model provides

\section{Key words}

ANAESTHETICS, VOLATILE: halothane;

LUNG: impedance, mechanics, airways, lung tissue, mathematical model.

From the Departments of Anaesthesiology, School of Medicine Chiba University, Chiba, Japan and *National Cancer Centre Hospital, Tokyo, Japan.

Address correspondence to: Dr. Jiro Sato, Department of Anaesthesiology, School of Medicine Chiba University, 1-8-1 Inohana Chuo-ku, Chiba, 260, Japan.

Accepted for publication 2nd January, 1995. a quantitative tool to assess lung mechanics precisely, if respiratory signals are measured only at the true airway opening.

Cette étude a pour objectifs d'examiner si lhalothane diminue le tonus contractile du poumon normal et de séparer les effets de lhalothane sur les voies aériennes de ceux de lhalothane sur le parenchyme pulmonaire. Nous avons aussi vérifié si un modèle mathématique était capable d'exprimer quantitativement les changements de mécanique pulmonarire produits par l'halothane. Nous avons mesuré limpédance pulmonaire $(Z L(\omega)$ fonction complexe d'éléments vrais (la résistance pulmonaire) et imaginaires (la réactance)) à basse fréquence sur des chiens avec une technique oscillatoire à volume forcé avant et pendant une anesthésie d̀ lhalothane MAC I. Lhalothane produit des changements minimes de $Z L(\omega)$. La résistance pulmonaire a tendance à augmenter pendant l'anesthésie à lhalothane alors que la réactance ne change pas. Grâce à une technique capsulaire séparant les voies aériennes du parenchyme pulmonaire, nous avons constaté que les changements mécaniques produisaient surtout des altérations parenchymateuses. Notre modèle mathématique comportait une voie aérienne communiquant à une aire alvéolaire entourée de tissu visco-élastique. Dans l'analyse du modèle, les estimés de la résistance et de linertance des voies aériennes diminuent après l'administration d'halothane. Par contre, les estimés de lélastance et de la résistance du parenchyme pulmonaire ne changent pas pendant l'anesthésie à lhalothane. Les résultats de la simulation ont été consistants avec ceux obtenus par des mesures directes de pression alvéolaires. Nos résultats suggèrent qu'une basse concentration d'halothane dilate les voies aériennes mais naltère pas la mécanique parenchymateuse du poumon normal, et que ce modèle constitue un outil quantitatif valide pour évaluer la mécanique pulmonaire avec précision si les signaux respiratoires sont mesurés au moment de l'ouverture des voies aériennes.

Halothane is a potent bronchodilator known to reduce. high pulmonary resistance when increased mechanical 
tone is produced by histamine, acetylcholine, or vagal stimulation. ${ }^{1-5}$ Recent studies have demonstrated that halothane decreases lung tissue resistance as well as airway resistance in excised lungs. ${ }^{6,7}$ In the low frequency range encompassing physiological breathing rates, a mathematical model proposed by Hantos et al. ${ }^{8}$ accurately depicted the mechanical property of the normal lung using only four variables - two for airways and two for lung tissue. The model stratified pulmonary changes into those of the airway and lung tissue components using lung mechanical impedance measured only at airway opening.

Our concerns were (i) whether halothane still exhibits its mechanical effect on a normal lung with a low contractile tone, and (ii) whether the above model approach is sensitive to detect small changes in lung mechanics. That is, whether the model could provide an accurate and indirect measure to distinguish the effects of halothane on airways from those on lung tissue. To address these issues, we tested the model directly using an alveolar capsule technique that measured the airway and tissue components of lung separately,

\section{Methods}

\section{Impedance and mathematical model}

In studying respiratory mechanics, two of the most familiar variables, coefficients, are resistance $(R)$ and elastance $(\mathrm{E})$. Compliance is reciprocal of $\mathrm{E}$. A simple lung model featuring the variables (Figure 1) is formulated by the following differential equation (the equation of motion),

$P(t)=R \dot{V}(t)+E V(t)$

where $P(t), \dot{V}(t)$, and $V(t)$ denote pressure, flow and ventilation volume (the integration of $\dot{V}(t)$ ) measured at airway opening, respectively, all of which are functions of time.

If we consider the lung as a linear mechanical system, it is characterized by a system function and not by a set of constant variables. The system function (also called transfer function) which is a function of frequency $(f)$ does not require any a priori model. Once the system

\section{GLOSSARY OF TERMS}

$\mathrm{Z}(\omega)$ : Mechanical impedance, a complex function of frequency $(f)$. $\omega$ : angular frequency, $\omega=2 \pi f$.

$\mathbf{R}(\omega)$ : real part of $\mathbf{Z}(\omega)$, referred as resistance.

$X(\omega)$ : imaginary part of $Z(\omega)$, referred as reactance.

$\mathrm{Z}(\omega)=\mathrm{R}(\omega)+i \mathrm{X}(\omega)$.

Subscripts L, TI, and AW denote lung, lung tissue, and airway, respectively. For example, $Z L(\omega), \operatorname{RTI}(\omega), \operatorname{XAW}(\omega)$ indicate lung impedance, lung tissue resistance, and airway reactance, respectively.

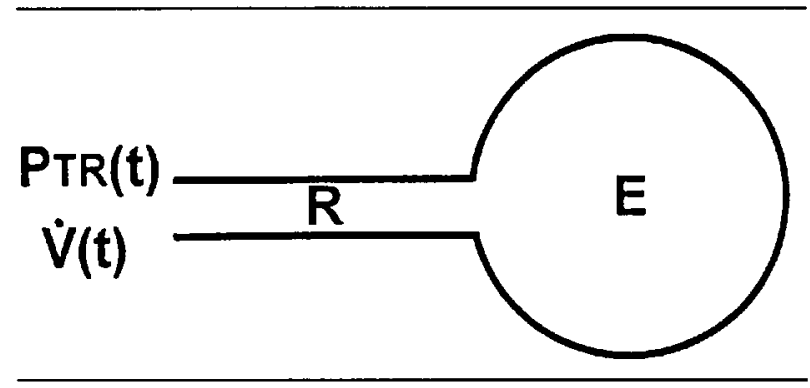

FIGURE 1 Single-compartment model. A single airway conduit is connected in series, mechanically in parallel, with a single alveolus. The mechanical properties of the airway and alveolar region are represented by two coefficients, a resistance $(R)$ and elastance $(E)$, respectively. $\operatorname{PTR}(t), \dot{V}(t)$ denote pressure and flow measured at airway opening.

function is defined, we can accurately predict the behaviour responding to whatever input is applied to the system. In a lung, the input and output are flow (V) and pressure (P) at airway opening, respectively, and the system function is the impedance $(\mathrm{ZL}(\omega))$, where $\omega$ is angular frequency $(\omega=2 \pi f)$. The $\mathrm{ZL}(\omega)$ is a complex function (a composite function of real and imaginary parts) and obtained as $\mathbf{P}(\omega) / \dot{\mathrm{V}}(\omega)$, where $\mathbf{P}(\omega)$ and $\dot{\mathrm{V}}(\omega)$ are the Fourier transforms of $P(t)$ and $\dot{V}(t)$, respectively. The real and imaginary parts are referred as resistance $(\operatorname{RL}(\omega))$ and reactance $(X L(\omega))$, respectively. Both $R_{L}(\omega)$ and $\mathrm{XL}(\omega)$ are functions but not single variables. The $Z\llcorner(\omega)$ of the lung model formulated by Eq. 1 is,

$$
\begin{aligned}
\mathrm{ZL}(\omega)=\mathrm{P}(\omega) / \dot{\mathrm{V}}(\omega)=\mathrm{R} L(\omega)+i \mathrm{XL}(\omega) & =\mathrm{R}-i \mathrm{E} / \omega
\end{aligned}
$$

where $i$ is an imaginary unit $\left(i^{2}=-1\right)$. As shown in Eq. 2, the lung model consists of $\mathrm{RL}(\omega)$ which takes a constant $R$ irrespective of frequency and $X_{L}(\omega)$ whose fundamental element is elastance $\mathrm{E}$.

As long as the above model fits a lung, it is sufficient to describe lung mechanics by the variables $\mathrm{R}$ and $\mathrm{E}$. However, RL $(\omega)$ exhibits frequency-dependent behaviour and that $X_{L}(\omega)$ is, in part, contributed by the lung tissue resistive property as well as by the elastance in lowfrequency range encompassing physiological breathing rates. ${ }^{8,10}$ This implies that neither $R L(\omega)$ nor $X_{L}(\omega)$ can be characterized only by the variables $R$ and $E$, respectively. However, it is difficult to use the whole function of $\mathbf{Z}(\omega)$ for statistical analyses. In this study, therefore, we resorted to a mathematical model which was physiologically plausible. The measured $\mathrm{ZL}(\omega)$ was fitted to the model which provided pararemter estimates, i.e., the estimated coefficients of the function. The effects of halothane on $Z L(\omega)$ were tested by comparing the changes in the model variables. Thus the comparison of $\mathrm{ZL}(\omega)$ 
functions was converted to a statistical problem testing pararmeter values.

We employed a lung model consisting of an airway connected in series with a single alveolus which was surrounded by visoelastic lung tissue ${ }^{8,10}$ It was developed to interpret the mechanical features of lung mentioned above. The model is schematically presented in Figure 2 and formulated as ${ }^{8}$

$$
\begin{aligned}
\mathrm{Z} L \omega=\hat{\mathrm{R}}+i \omega \hat{\mathrm{I}} & +\hat{\mathrm{B}} \pi / 4.6 \omega \\
& -i(\hat{\mathrm{A}}+0.25 \hat{\mathrm{B}}+\hat{\mathrm{B}} \log \omega) / \omega
\end{aligned}
$$

where the model parameters $\hat{R}$ and $\hat{I}$ denote airway resistance and inertance of airway gas, and $\hat{\mathrm{A}}$ and $\hat{\mathrm{B}}$ lung tissue elastance and resistance, respectively.

The $\mathrm{Z} u(\omega)$ measured at frequencies from zero to several $\mathrm{Hz}$ reflects the mechanical properties of both airways and lung parenchyma. ${ }^{8,9}$ The $R L(\omega)$ at low frequencies, largely the frequency-dependent segment, describes mainly the tissue resistive property, which is represented by the variable $\hat{B}$. On the other hand, the frequencyindependent asymptotic segment at high frequencies indicates airway resistance, and is expressed by $\hat{R}$. $X L(\omega)$ is characterized by lung tissue mechanical constituents - tissue's resistive $(\hat{\mathrm{B}})$ and elastic $(\hat{\mathrm{A}})$ properties, although the elastance still bears a determinant role. Inertance of airway gas (I) is also included in $\mathrm{XL}_{\mathrm{L}}(\omega)$ for its appreciable contribution at high frequencies.

When measurement is performed only at a single frequency such as sinusoidal ventilation even in such the lung formulated by $E q .3$, both $R L(\omega)$ and $X L(\omega)$ take a single constants instead of functions since $(\omega)$ is a single value.

$\mathrm{RL}(\omega)=\hat{\mathrm{R}}+\hat{\mathrm{B}} \pi / 4.6 \omega$

$\mathrm{XL}(\omega)=\omega \hat{\mathrm{I}}-i(\hat{\mathrm{A}}+0.25 \hat{\mathrm{B}}+\hat{\mathrm{B}} \log \omega) / \omega$

Substituting these constants, $R L(\omega)$ and $-\omega X L(\omega)$, into $R$ and $E$ in Eq. 1, respectively, yields the differential equation of the single compartment model. It implies that the mechanical feature of lung represented in Eq. 3 cannot be manifested from the single-frequency measurement. This is approximately the case for the measurements during spontaneous breathing or mechanical ventilation as in the previous studies. ${ }^{1-5}$

\section{Experiments}

The study was approved by the Ethics Committee of the Laboratory Animal Centre, School of Medicine, Chiba University. The experimental setup is illustrated in Figure 3. We studied six mongrel dogs weighing $17-19 \mathrm{~kg}$. The animal anaesthetized with pentobarbitone, $25 \mathrm{mg} \cdot \mathrm{kg}^{-1}$ $i v$, tracheotomized, and a cannula was inserted into the trachea. A three-way stopcock was connected to the tracheal

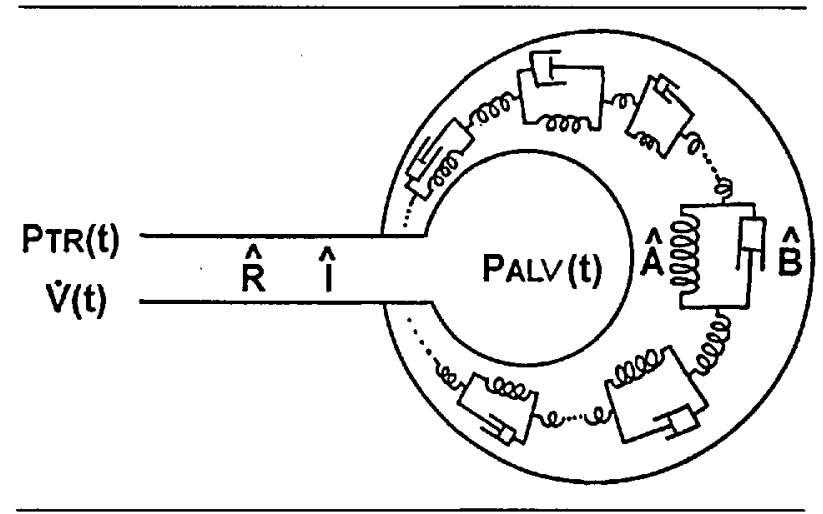

FIGURE 2 Model fitted to the measured lung impedance $Z L(\omega)$. The model has the similar structure to the single-compartment model shown in Figure 1. In the model, however, the lung tissue mechanical property is described by a continuous distribution of springs and dashpots which are expressed by elastance $(\hat{\mathrm{A}})$ and resistance $(\hat{\mathrm{B}})$ parameters, respectively. The airway has an inertance of airway gas (i) for its substantial contribution at high frequencies as well as a resistance $(\hat{R})$. PALv( $(t)$ denotes the characteristic alveolar pressure.

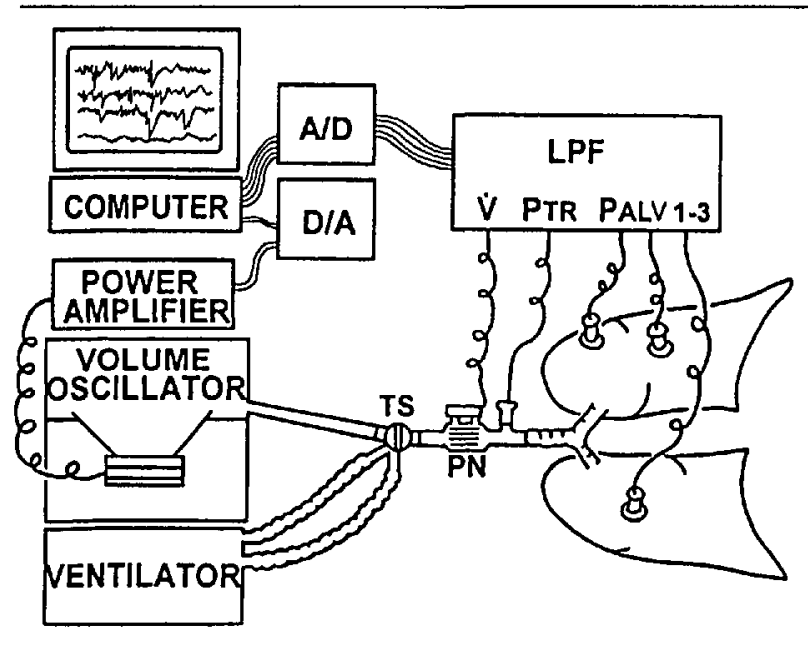

FIGURE 3 Experimental setup. A/D, analogue-to-digital converter; D/A, Digital-to-analogue converter; LPF, low-pass filter, TS, threeway stopcock; and PN, pneumotachograph. Regional alveolar pressures (PALV 1-3) were measured at three different lobes.

cannula to allow switching between a mechanical ventilator (Aika EVA800, Bunkyo, Tokyo) and a forcedvolume oscillation device (see below). The dogs were paralysed using pancuronium bromide, $2.0 \mathrm{mg}$, and their lungs mechanically ventilated with $100 \% \mathrm{O}_{2}$, using a tidal volume of $12 \mathrm{ml} \cdot \mathrm{kg}^{-1}$. End-tidal expired carbon dioxide tension was continuously monitored (Capnox Nippon Colin, Nagoya, Japan) and kept between 4.0-4.7 kPa. Arterial pressure was continuously monitored via a catheter placed into the left femoral artery. Anaesthesia was maintained by a continous infusion of pentobarbitone 
(3-4 $\mathrm{mg} \cdot \mathrm{kg}^{-1} \cdot \mathrm{hr}^{-1}$ ), which provided a stable circulatory condition. In addition, pancuronium bromide $(1.0 \mathrm{mg})$ was given every $30 \mathrm{~min}$ to maintain paralysis.

The sternum was widely split to expose as much lung surface as possible. After the chest was opened, positive end-expiratory pressure (PEEP) of $0.5 \mathrm{kPa}$ was added to the mechanical ventilation. We assumed that PEEP maintained functional residual capacity (FRC) approximately equal to that with the chest intact. A total lung capacity manoeuvre (five consecutive hyperinflations using a maximum tracheal pressure of $2.5 \mathrm{kPa}$ ) was performed every $15 \mathrm{~min}$ to prevent absorption atelectasis. Alveolar pressure was measured at three different regions in the upper and/or middle lobes of both left and right lungs, employing an alveolar capsule technique. The technique is described in detail elsewhere. ${ }^{9,11}$ Briefly, a capsule was affixed on to one lobe. The pleural surface under each capsule was punctured with an electrocautery needle to make four to six holes. The pressure inside each capsule was measured with a piezoresistive transducer (ICS 12002G, ICSensors, Milpitas, CA). Characteristic alveolar pressure (PALV) was taken as the mean of three capsule pressures. Tracheal pressure (PTR) was measured at a side port of the tracheal cannula using another piezoresistive transducer. Airway flow $(\dot{V})$ was measured between the three-way stopcock and the tracheal cannula with a Fleisch \#2 pneumotachograph connected to a differential piezoresistive transducer (Microswitch 163PCO1D36, Honeywell, Shibuya, Tokyo). All signals were low-pass filtered at $20 \mathrm{~Hz}$ (SPA-3, three-pole Butterworth filter, TechnoService, Urayasu, Chiba), digitized at $81.92 \mathrm{~Hz}$ (A/D converter DT2801-A, Data Translation, Marlboro, MA, USA), and stored in a computer. Data were collected and partly processed by ANADAT/ LABDAT data acquisition and analysis software package (RHT-InfoDat, Montreal, Quebec). The alveolar capsule technique was employed to separate airways from lung tissue mechanics. It assumed a mechanically parallel connection of airways with lung parenchymal components, being represented,

$\mathrm{ZL}(\omega)=\mathrm{ZAW}_{\mathrm{A}}(\omega)+\mathrm{ZTI}_{\mathrm{T}}(\omega)$

$\operatorname{Ru}(\omega)=\operatorname{RAw}(\omega)+\operatorname{RTl}(\omega)$

$\mathrm{X} L(\omega)=\mathrm{XAW}_{(\omega)}+\mathrm{XTI}(\omega)$

where the abbreviations are indicated in the Glossary. After all the measurements had been performed, the dogs were sacrificed with $\mathrm{KCl}$, iv.

\section{Impedance measurements}

A pseudorandom forced-volume oscillation technique was used to measure $\mathrm{Z} L(\omega) .{ }^{9}$ We used a computer signal which was a composite of 14 sinusoids whose frequencies ranged between 0.08 to $5.32 \mathrm{~Hz}$. The signal was used to drive a computer-driven volume oscillator (a loudspeaker in a box system) which was in turn connected to one port of the three-way stopcock. The actual volumes of excursions were approximately $30 \mathrm{ml}$.

Measurement of $\mathrm{ZL}_{L}(\omega)$ was achieved as follows. Mechanical ventilation was stopped at end-expiration (at 0.5 $\mathrm{kPa}$ PEEP) and the three-way stopcock switched to the volume oscillator. After three seconds apnoea, forced oscillation was applied for $37.5 \mathrm{sec}$ while all the signals were recorded. The procedure was repeated five times with a two-minute interval of mechanical ventilation separating each run, and the five sets of measurements were averaged to reduce noises (control test). The first three seconds of averaged signals were discarded to reduce the effect of start-up transients of impedance computation. The $\mathrm{Z} \mathrm{L}(\omega)$ was computed using auto- and crosscorrelation analysis ${ }^{9}$ employing the equation,

$\mathrm{ZL}(\omega)=\operatorname{PTR}(\omega) / \dot{V}(\omega)$.

This was followed by ventilation with $\mathrm{O}_{2}$ containing 1 MAC $(0.87 \%)$ halothane. The concentration of halothane in the respiratory gas was continuously monitored by an infrared anaesthetic gas monitor (Capnox, Nippon Colin, Nagoya, Japan) and the end-expiratory concentration was maintained at 1 MAC. After 30 minutes, five more oscillation measurements were performed and $Z \mathbf{L}(\omega)$ determined again (halothane test). We also computed lung tissue impedance $\mathrm{ZTI}(\omega)$ as,

$\mathrm{ZTI}(\omega)=\operatorname{PALV}(\omega) / \dot{\mathrm{V}}(\omega)$

Assuming the difference between PTR and PALV as a pressure drop across a characteristic airway, airway impedance, $\operatorname{ZAW}(\omega)$, was computed as,

$\mathrm{ZAW}(\omega)=\mathrm{ZL}(\omega)-\mathrm{ZTI}(\omega)$

\section{Model fitting}

We fitted the measured $Z_{L}(\omega)$ to the mathematical model which was described by Eq. 3. Model parameters were estimated using a nonlinear least-squares technique that minimized the normalized sum of squared residuals, SSR, between the measured $\mathrm{Z}_{\mathrm{L}}(\omega)$ and the model,

$$
\begin{array}{r}
\operatorname{SSR}=\frac{1}{N-m} \sum_{i=1}^{N}\left\{\frac{\left[R_{L}\left(\omega_{i}\right)-\hat{R}_{L}\left(\omega_{i}\right)\right]^{2}}{R_{L}\left(\omega_{i}\right)^{2}}\right. \\
\left.+\frac{\left[X_{L}\left(\omega_{i}\right)-\hat{X}_{L}\left(\omega_{i}\right)\right]^{2}}{X_{L}\left(\omega_{i}\right)^{2}}\right\}
\end{array}
$$

where $\mathrm{N}$ represented the number of data points, $\mathrm{m}$ was the number of parameters, i.e., four, in the model. The $\hat{R} L(\omega)$ and $\hat{X} L(\omega)$ were the model estimates of $R L(\omega)$ and $X_{L}(\omega)$, respectively. Statistical differences were tested 

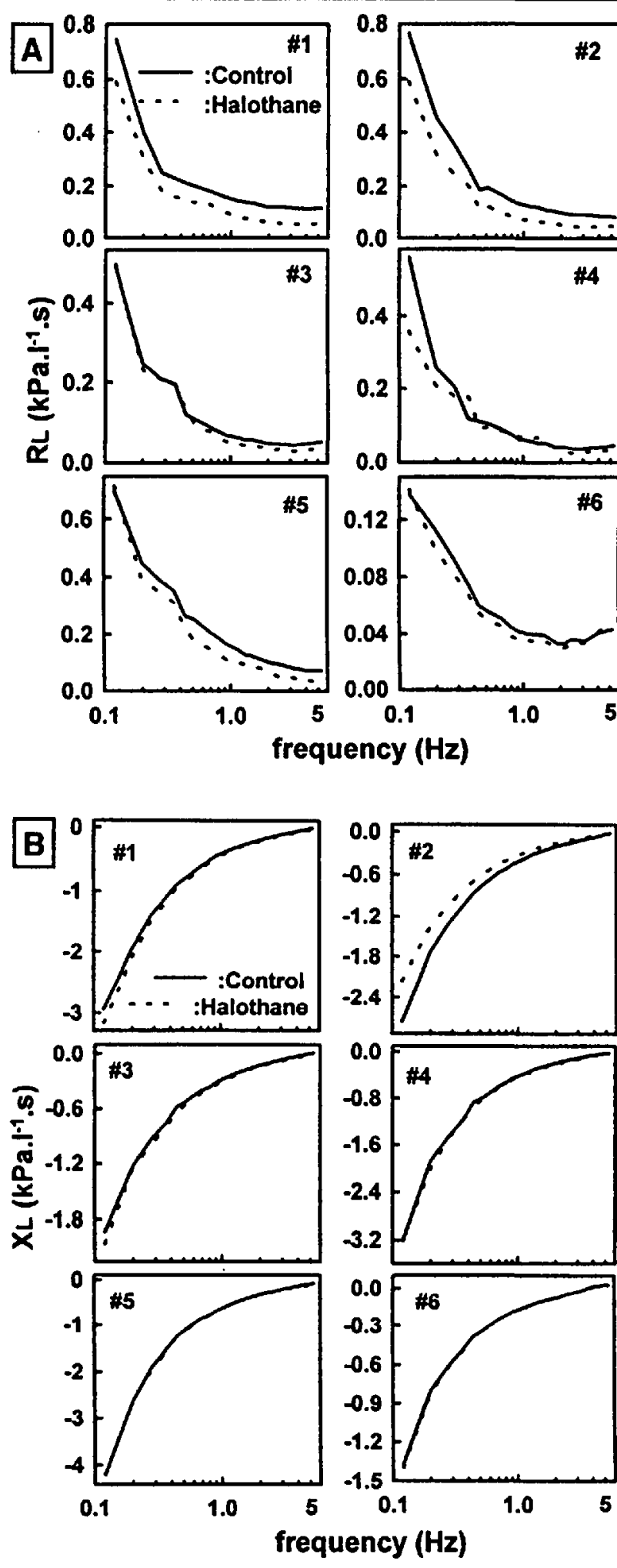

FIGURE 4 The $Z L(\omega)$ measured in six individual dogs. The RL( $\omega)$ (Figure 4, A) and XL( $\omega$ ) (Figure 4, B) are plotted against a log scale of frequency to clarify the difference between the two conditions at low frequencies. Solid and dashed lines represent $\mathrm{Z} L(\omega)$ measured under control and halothane conditions, respectively.

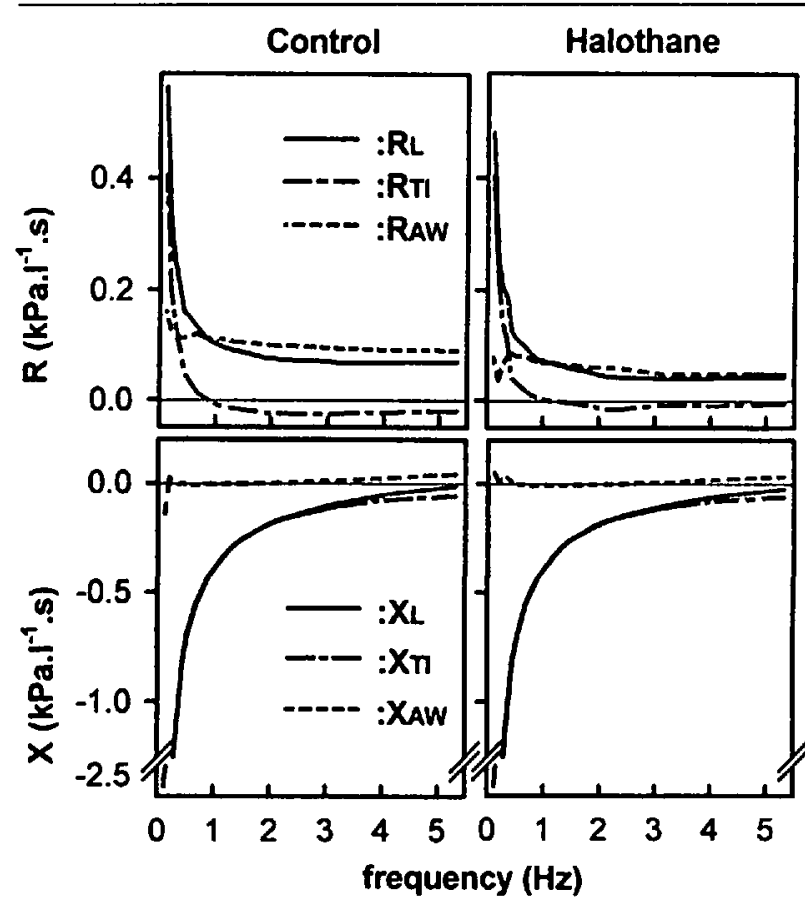

FIGURE $S$ The relationship between $Z \mathrm{Z}(\omega), \mathrm{ZTI}(\omega)$, and $\mathrm{ZAW}(\omega)$ measured at control and halothane conditions. All the six dogs exhibited the similar relationship between the three impedances. Therefore, data represent the means of six dogs. Standand error bars were omitted for simplicity. Top and bottom panels represent the resistances and reactances, respectively. Solid, dash-dot, and dashed lines represent $\mathrm{ZL}(\omega), \mathrm{ZTI}(\omega)$, and $\mathrm{ZAW}(\omega)$, respectively.

using Student's paired t-test and were considered significant when the $P$ value was $<0.05$.

\section{Results}

Figure 4 illustrates $\mathrm{ZL}(\omega)$ obtained in individual dogs at control and halothane. The RL $(\omega)$ (Figure 4, A) exhibited a frequency dependency that has been well documented in other studies. ${ }^{8,12-14}$ The RL $(\omega)$ tended to shift downward in three dogs during halothane anaesthesia, under the studied frequencies (Dogs \#1, 2 and 5), while the other three dogs showed only a minimal decrease in RL( $\omega)$ (Dogs \#3, 4 and 6). Halothane did not seem to produce any consistent change in $X_{L}(\omega)$ (Figure 4, B).

Figure 5 depicts the relationship between $\mathrm{ZL}(\omega), \mathrm{ZTI}(\omega)$ and $\operatorname{ZAw}(\omega)$ under both experimental conditions. The RAw $(\omega)$ (Figure 5, upper panels) was approximately constant over the frequency range while $\operatorname{XAw}(\omega)$ (Figure 5, lower panels) became slightly positive with increased frequency, indicating that the airways behaved roughly as a resistance-inertance system at this frequency range. ${ }^{8,9,13}$ Although $\operatorname{RAw}(\omega)$ slightly exceeded $\mathrm{R} L(\omega)$ at higher frequencies, it essentially approached $\mathrm{RL}(\omega)$ at higher frequencies when $\mathrm{X} L(\omega)$ was rapidly approaching zero. This indicated that the resistive component of $\mathrm{ZTI}(\omega)$ became 


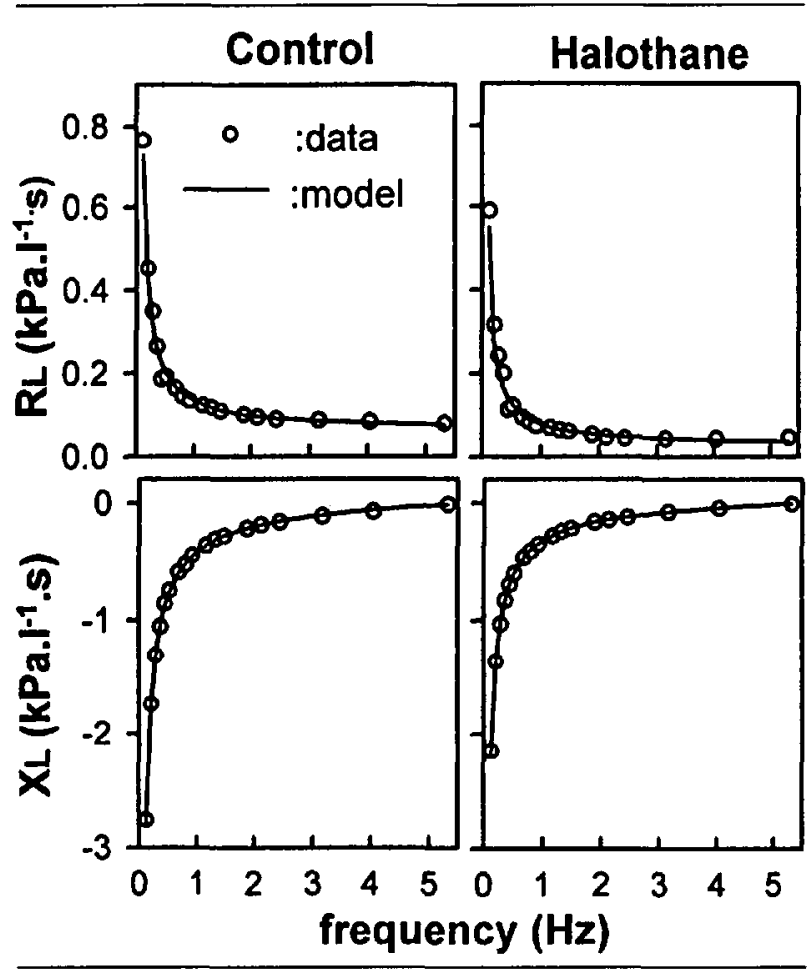

FIGURE 6 Model fitting and actual $Z L(\omega)$ measured at two different treatments in a representative $\operatorname{dog}(\operatorname{dog} \# 2)$. Open circles denote measured $\mathrm{ZL}(\omega)$ and solid lines represent depictions of the model.

negligible at these frequencies, and that the tissue behaved as an elastance-inertance system at higher frequencies. Halothane seemed to reduce RAw $(\omega)$ compared with control, whereas $\operatorname{RTI}(\omega)$ was not influenced by halothane. Furthermore, any of the reactances $(\mathrm{XL}(\omega), \mathrm{XTI}(\omega)$, and $\mathrm{XAW}(\omega))$ remained unchanged during halothane anaesthesia.

Figure 6 shows an example of the estimated $Z_{L}(\omega)$ using our model in a representative $\operatorname{dog}(\operatorname{Dog} \# 2)$ at control and halothane. The predicted values agreed with measured $Z_{L}(\omega)$ values very accurately at both experimental conditions. Estimated values of model parameters are listed in the Table. Both airway parameters $\hat{R}$ and I were significantly reduced by halothane compared with control, whereas lung tissue parameters $\hat{A}$ and $\widehat{B}$ were unaffected.

\section{Discussion}

Our study indicates that $1 \mathrm{MAC}$ halothane reduces airway resistance and inertance, but had no influence on lung tissue mechanical properties, resulting in small changes in $\mathrm{ZL}(\omega)$. We also demonstrated that the effect of halothane on lung mechanics could be described using a simple four-variable model.

The lung consists of airways and lung tissue compo-
TABLE Results of model fitting to lung impedance data

\begin{tabular}{lll}
\hline Parameter & Control & Halothane \\
\hline $\mathrm{SSR}\left(\times 10^{-2}\right)$ & $1.88 \pm 0.97$ & $2.23 \pm 1.61$ \\
$\mathrm{R}\left(\times 10^{-2} \mathrm{kPa} \cdot \mathrm{L}^{-1} \cdot \mathrm{s}\right)$ & $5.03 \pm 2.56$ & $2.42 \pm 0.78^{*}$ \\
$\hat{\mathrm{I}}\left(\times 10^{-3} \mathrm{kPa} \cdot \mathrm{L}^{-1} \cdot \mathrm{s}^{2}\right)$ & $2.19 \pm 0.23$ & $1.83 \pm 0.37^{*}$ \\
$\hat{\mathrm{A}}\left(\mathrm{kPa} \cdot \mathrm{L}^{-1}\right)$ & $2.00 \pm 0.65$ & $2.02 \pm 0.69$ \\
$\hat{\mathrm{B}}\left(\times 10^{-1} \mathrm{kPa} \cdot \mathrm{L}^{-1}\right)$ & $4.88 \pm 2.25$ & $4.41 \pm 2.01$ \\
\hline
\end{tabular}

Values are means \pm SD from six dogs. SSR: minimum values of the SSR. $\hat{R}$ and $\hat{I}$ : airway resistance and inertance, respectively. $\hat{A}$ and $\mathrm{B}$ : tissue elastance and resistance, respectively.

*Statistical difference $(P<0.05)$ between control and halothane values.

nents. Studies examining each component have been extensively performed in recent years using the alveolar capsule technique. ${ }^{9,11,13.16}$ These studies have demonstrated that in the low-frequency interval encompassing physiological breathing rates (a) that $R \Psi(\omega)$ exhibits a remarkable frequency dependency with a large proportion accounted for by lung tissues, (b) that the contribution of $\operatorname{RTI}(\omega)$ to $\operatorname{RL}(\omega)$ is increasingly greater than $\operatorname{RAw}(\omega)$ as frequency decreases, and (c) that the manifestation of inhomogeneous ventilation is negligible under normal conditions. ${ }^{8,9,16,17}$ Our separation of airways from lung tissue using the alveolar capsule technique demonstrated that RAw $(\omega)$ becomes even greater than $\mathrm{RL}(\omega)$ at frequencies greater than approximately $1 \mathrm{~Hz}$ (Figure 5). As pointed out previously 9,17 this may be because the entire alveolar pressure was approximated only by a small number of capsule pressures. When considerable ventilation inhomogeneity is present, however, $\mathrm{ZAW}(\omega)$ exhibits a characteristic frequency dependent behaviour. ${ }^{9,16,18}$ This is in contrast to that observed in the present study, i.e., an almost constant $\operatorname{RAW}(\omega)$ and a linear $\operatorname{XaW}(\omega)$. Our results, therefore, suggest that the lung behaved homogenously under control and halothane conditions. A careful examination of Figure 5 suggests that halothane reduced RAw $(\omega)$. Halothane, on the other hand, did not produce noticeable changes in $\mathrm{ZTI}(\omega)$ (Figure 5), indicating that, at the concentration used in the present experiment, it does not alter the mechanical property of parenchymal tissue in the normal lung. Our results are in contrast to those of Vettermann et al. ${ }^{6}$ demonstrating that halothane reduced $R L(\omega)$ and simultaneously decreased $\operatorname{RAw}(\omega)$ and $\operatorname{RTI}(\omega)$ in a range of frequencies below 1 $\mathrm{Hz}$ in the excised canine lung. The discrepancy may be due to methodological differences, halothane concentration, input magnitude (lung volume excursions) and animal preparation (intact versus excised lung). In this regard these investigators noted a postmortem increase in the tone of lung contractile elements. Whereas airway mechanics are governed largely by airway smooth muscles, ${ }^{19}$ lung tissue rheological property is, in contrast, de- 
termined by a variety of mechanical factors including elastic and collagen frbres and their network structure, gas-liquid interface on alveolar surface, smooth muscle in the entrance ring of alveolar duct, contractile interstitial cells, and contractile elements in peripheral vasculature. ${ }^{20,21} \mathrm{~A}$ low concentration of halothane may not induce mechanical changes in all these tissues. However, our results suggest that at low concentration halothane may act prophylactically against bronchoconstriction by stabilizing airway smooth muscle tone particularly in patients with hypereactive airways.

When $\mathrm{ZL}(\omega)$ changes its frequency-dependent shape in response to an intervention as in this study, it prevents simple statistical analysis from assessing the effect of the intervention on $\mathrm{ZL}(\omega)$. In this respect, parameter estimation with a mathematical model provides a useful statistical alternative by simply comparing the changes in the parameter values produced by the intervention, since the set of the parameters expresses both shape and magnitude of $Z_{L}(\omega)$. Furthermore the changes observed in model parameters imply those occurred in certain physiological or mechanical characteristics within a whole lung.

Our study demonstrated that the model employed showed an excellent fit to low frequency impedance measurement in normal dogs, and that parameters used in the model accurately depicted mechanical properties of airways and lung tissue in the normal dog. ${ }^{8,9,16}$ As the capsule study suggests that halothane does not increase uneven ventilation, this model may be suited for analysing the effect of halothane on lung mechanics. Our parameter estimation showed a decrease in both $\mathrm{R}$ and $\mathrm{I}$ during halothane anaesthesia suggesting that halothane dilated the airway, which was consistent with the alveolar capsule study (Figure 5). In contrast, halothane had no effect on lung tissue parameters $\hat{A}$ and $\hat{B}$. The predicted values were consistent with those measured directly by alveolar capsule technique. Although the model employed is simple and has only four parameters, it may provide reliable information on lung mechanics by separating airways from lung tissue. Since such analysis requires only input impedance, i.e., measurement of flow and pressure at airway opening, it may be easily applied in a clinical situation.

In summary, we measured lung impedance at low frequencies before and during halothane anaesthesia in normal dogs. Halothane at $1 \mathrm{MAC}$ dilated airways, resulting in a decrease in airway resistance and inertance. On the other hand, halothane did not exert any effect on lung tissue mechanical property. The impedance data were well described by a model which featured a single airway conduit leading to a viscoelastic lung tissue. The model analysis produced results that were consistent with direct alveolar pressure measurements.

\section{References}

1 Hermens $J M$, Edelstein E, Hanifin JM, Woodward WR, Hirshman $C A$. Inhalational anesthesia and histamine release during bronchospasm. Anesthesiology 1984; 61 : 69-72.

2 Hickey $R$, Graf $P D$, Nadel JA, Larson CP Jr. The effects of halothane and cyclopropane on total pulmonary resistance in the dog. Anesthesiology 1969; 31: 334-43.

3 Hirshman CA, Bergman NA. Halothane and enflurane protect against bronchospasm in an asthma dog model. Anesth Analg 1978; 57: 629-33.

4 Hirshman CA, Edelstein G, Peetz S, Wayne R, Downes H. Mechanism of action of inhalational anesthesia on airways. Anesthesiology 1982; 56: 107-11.

5 Shah MV, Hirshman CA. Mode of action of halothane on histamine-induced airway constriction in dogs with reactive airways. Anesthesiology 1986; 65: 170-4.

6 Vettermann J, Warner WO, Brichant J-F, Rehder. Halothane decreases both tissue and airway resistances in excised canine lungs. J Appl Physiol 1989; 66: 2698-703.

7 Warner WO, Vettermann J, Brusasco V, Rehder $K$ Pulmonary resistance during halothane anesthesia is not determined only by airway caliber. Anesthesiology 1989; 70: 453-60.

8 Hantos Z, Daroczy B, Csendes T, Suki D, Nagy S. Modelling of low-frequency pulmonary impedance in dogs. J Appl Physiol 1990; 68: 849-60.

9 Sato J, Suki B, Davey BLK, Bates JHT. Effect of methacholine on low frequency mechanics of canine airways and lung tissue. J Appl Physiol 1993; 75: 55-62.

10 Hildebrandt $J$. Pressure-volume data of cat lung interpreted by a plastoelastic, linear viscoelastic model. J Appl Physiol 1970; 28: 365-72.

11 Fredberg JJ, Ingram RH Jr, Castile RG, Glass GL, Drazen $J M$. Nonhomogeneity of lung response to inhaled histamine assessed with alveolar capsules. J Appl Physiol 1987; 58: 1914-22.

12 Bates JHT, Shardonofsky F, Stewart DE. The lowfrequency dependence of respiratory system resistance and elastance in normal dogs. Respir Physiol 1989; 78: 369-82.

13 Sato J, Davey BLK, Shardonofsky F, Bates JHT. Lowfrequency respiratory system resistance in the normal dog during mechanical ventilation. J Appl Physiol 1991; 70: 1536-43.

14 Suki B, Peslin R, Diwivier C, Farre R. Lung impedance in healthy humans measured by forced oscillations from 0.01 to $0.1 \mathrm{~Hz}$. J Appl Physiol 1989; 67: 1623-9.

15 Warner WO, Vettermann J, Brichant J-F, Rehder $K$. Direct and neurally mediated effects of halothane on pulmonary resistance in vivo. Anesthesiology 1990; 72: 1057-63.

16 Hantos Z, Daroczy B, Suki B, Nagy S, Fredberg JJ. Input 
impedance and peripheral inhomogeneity of dog lungs. $J$ Appl Physiol 1992; 72: 168-78.

17 Petak H, Hantos Z, Adamicza A, Daroczy B. Partitioning of pulmonary impedance: modelling vs. alveolar capsule approach. J Appl Physiol 1993; 75: 513-21.

18 Fredberg $J J$, Mead $J$. Impedance of intrathoracic airway models during low-frequency periodic flow. J Appl Physiol 1979; 47: 347-51.

19 Stephens NL, Hoppin FG Jr. Mechanical properties of airway smooth muscle. In: Macklem PT, Mead J (Eds.)

Handbook of Physiology. Mechanics of Breathing, vol III. Bethesda, Maryland: American Physiology Society, 1986; 263-76.

20 Fredberg JJ, Stamenovic $D$. On the imperfect elasticity of lung tissue. J Appl Physiol 1989; 67: 2408-19.

21 Hoppin FG Jr, Stothert JC Jr, Greaves IA, Lai Y-L, Hildebrandt $J$. Lung recoil: elastic and rheological properties. In: Macklem PT, Mead J (Eds.). Handbook of Physiology, Mechanics of Breathing, vol III Bethesda, Maryland: American Physiology Society, 1986; 195-216. 